\title{
Conclusion: Strategic Learning and Situational High Reliability
}

Serious disasters in the form of collapsing bridges and buildings that claim the lives of people are rare for a reason. The standard risks are known, they are being addressed by regulation and the regulation is being enforced by public authorities. While any such tragedy has a single specific technical root cause, typically a serious structural design error, the non-technical origins of the disasters seem to be complex at first glance. Accordingly, related findings seem to defy generalization. Which, if true, would imply serious limitations for learning and prevention. The cases analyzed in this book, however, tell otherwise. They do reveal patterns of generalizable causal mechanisms that highlight exemplary risk zones and, thus, prospects for mindful prevention.

\subsection{A Summary}

Melbourne's West Gate Bridge suffered a whole syndrome of anomalies. One affected public control and oversight, a second one the contractual arrangements between the authority in charge and contractors plus consultants, a third one the method of erection itself. In a way, it was too much of complexity. Yet, complexity as such was not the problem. Control of complexity would have been possible but control structures and intentions were weak or weakened in several dimensions.

There was no true public authority in charge. The Lower Yarra Crossing Authority was a QUANGO-a quasi-non-governmental organization- 
established on the initiative of the local business community to which the state of Victoria had delegated regulatory powers and enforcement competence. This arrangement not only diluted the representation of the public interest in a formal sense but also in practical terms. As a private institution, the Lower Yarra Crossing Authority was not part of the state budget but, instead, working with borrowed money to be refinanced through a toll fee once the bridge would be in use. What could have been anticipated was that timing and adherence to schedule was the weak flank of this arrangement. When quarrels with the labor unions entangled in rivalry and turf wars escalated, causing a serious delay of the basic steelworks of the bridge, the Lower Yarra Crossing Authority found itself between the proverbial rock and a hard place. The question was whether to stick to the arrangement that included a penalty fee to be paid by the relevant contractor in case of delay without accelerating the construction process in any way or to relinquish the contractor and reducing his role to occasional consultancy. In March 1970, the Authority took the second option. As a consequence, a local contractor with no experience with the construction and erection of steel box girder bridges assumed responsibility for the completion of the works that were particularly complex and demanding anyway. The initial contractor, a Dutch-based international corporation, had decided to assemble the steel boxes of the girders on the ground which necessitated to lift them up and to bolt the various parts of the box girders together up in the air. It was in this complicated and vulnerable process that inaccuracies occurred whose ill-fated repair triggered the disaster of 15 October 1970.

So the critical juncture at which the disaster became almost inevitable was passed relatively early, seven months before the bridge, still under construction, actually collapsed. The semi-private status of the Lower Yarra Crossing Authority and a fragile contractual arrangements weakened control where control should have been of the essence. In the case analysis of Chap. 2 this is characterized as a risk increasing 'situational mechanism'. By the same token, however, the risk increasing effects could have been neutralized at the level of the 'action formation mechanisms' where mindful intervention was both required and possible. However, 'action formation' was shaped by selective perceptions and silo-thinking. What emerged was rivalry, withheld information and a mood of general annoyance if not frustration. The Lower Yarra Crossing Authority turned out to be incapable of regaining a minimum of coordination capacity. As a consequence, the threshold between 'action formation mechanisms' and 
'transformational mechanisms' was perforated as well. The real point of no return was passed on 16 September 1970 when, in an on-site meeting of contractors and consultants, a discussion of the overall safety margins of the bridge did emerge but remained inconclusive since nobody insisted on renewed structural analyses and calculations.

What the case analysis reveals is, accordingly, that structural risk zones in the form of fragmented and poorly coordinated governance had not only been deliberately created but also remained untouched even when the risk increasing effects materialized. The characteristic syndrome remained the absence of true leadership and organized irresponsibility. The Lower Yarra Crossing Authority did not live up to that requirement which was virtually the consequence of its own nature as a hybrid institution being half private and half public and, thus, without real authority and enforcement capacity when smooth cooperation and diligence was indispensable.

Unlike the Lower Yarra Crossing Authority, the Minnesota Department of Transportation was in full control of all relevant aspects as far as safety issues and the maintenance of the I-35W Bridge were concerned. The bridge was 40 years in use when it collapsed on 1 August 2006. The technical core of the matter was the failure of gusset plates that kept the steel truss structure of the bridge together. The root cause of the disaster, however, was again non-technical in nature. The bottom line was information asymmetry among relevant actors and institutions and, as a consequence, the loss of information that otherwise could and should have been available or mobilized in the course of inspections that, ironically enough, did take place on a regular basis throughout the lifespan of the bridge. The 'situational mechanisms' creating risk increasing behavioral patterns within the Minnesota Department of Transportation (MnDOT) were characterized by uncompensated fragmentation of jurisdiction and red tape routines in lieu of case-by-case scrutiny and in-depth diligence of inspections. Moreover, the regular inspections were carried out by repair staff instead of engineers and by inspectors not even systematically trained in bridge inspections.

What emerged at the level of 'action formation mechanisms' is known as "normalization of deviance" and goal displacement in the sense that standard operating procedures designed for particular purposes-proper maintenance-became hollow and an end in themselves. In the essence,

\footnotetext{
${ }^{1}$ Diane Vaughan: The Dark Side of Organizations: Mistake, Misconduct, and Disaster. Annual Review of Sociology 25 (1999): 271-305.
} 
inspection routines turned into the fiction of inspection. Inspections were carried out on both an annual basis and in the form of so-called fracture critical inspections as supposedly in-depth assessments focusing on the especially vulnerable parts of the steel truss structure of the bridge. Several of these fracture critical inspection reports had even stated from the early 1990s on that the I-35W bridge was "structurally deficient". The epitome of neglect was an almost systematic lack of documentation within the Minnesota Department of Transportation whose "oral culture" was notorious. Another vicious circle established in the interaction between 'situational mechanisms' and 'action formation mechanisms' was connected to insufficient maintenance funds. Contractors were thus tempted to adapt their offer for necessary inspections and repairs accordingly. As a consequence, and in addition to an already diluted inspection practice, the diligence of inspections became subject to implicit or explicit negotiations between contractors and the Minnesota Department of Transportation. Which almost inevitably came at the expense of accuracy and thoroughness of the inspections.

As a result, the roles of private and public actors were inversed. The productive impulse of a Minneapolis based consultancy firm to conduct a revision of all fracture critical truss members of the bridge was stifled by the MnDOT which itself should have been the first advocate of sound inspections and safety measures. Again, it was ultimately the absence of leadership in terms of coordination efforts and mindfulness that created a situation in which the fundamental design error affecting the gusset plates remained undetected. Which was only to a limited degree the consequence of the financial restrictions to which the Minnesota Department of Transportation was exposed. It was primarily due to a culture of neglect and sloppiness that MnDOT officials remained unaware of the fact that damaged gusset plates had been depicted in series of photographs taken in the course of two subsequent inspections performed in 1999 and 2003. It was at exactly the same nodes of the steel truss that the bridge span started to disintegrate on 1 August 2007, when, nine days earlier, a great amount of additional weight in the form of cement and construction material had been placed on the deck of the bridge in preparation of repair works.

Regardless of the fact that the weakness of the gusset plates had been the proverbial unknown unknowns since the opening of the bridge in 1967 there was clearly one missed opportunity at which those structural flaws could have been detected. That moment came when, in January 2007, the Minnesota Department of Transportation decided to perform a 
cheaper "ultrasonic non-destructive examination" of only a couple of members of the steel truss of the bridge instead of a comprehensive retrofit of the 52 fracture critical truss members already specified by the relevant contractor. It was, basically, intended ignorance. The fact that the designers of the bridge, back in the 1960s, had failed to submit specific calculations for the gusset plates of the steel truss remained unrecognized throughout the life span of the bridge.

The characteristics of the non-technical root causes of the collapse of the CTV building in Christchurch in 2011 are stunningly similar to those of the I-35W bridge disaster. It was about a self-inflicted 'unknown unknown' in the form of a design error whose persistence had a parallel in a persistent culture of sub-standard performance of the building authority, the Christchurch City Council (CCC). Another parallel was the soft institutional backbone of both the Minneapolis Department of Transportation and the Christchurch City Council in their relationship with contractors and consultants. Neither institution had insisted when documentation submitted by consultants and contractors was incomplete. Relevant calculations were missing so that the authorities had virtually no basis for their review and the subsequent issuance of building permits.

So, just like in the case of the I-35W bridge, a first critical juncture decisively shaping the subsequent pathway of what resulted in the collapse of the CTV building was reached at an early stage. The crucial omission occurred when the CCC's responsible buildings engineer was persuaded by the owner of the relevant consultancy firm that previously stated concerns of the CCC's civil engineer in charge about potential structural design errors and missing calculations were unfounded. This episode was indicative of blurred responsibilities not only within the CCC but also between the authority and its own client, the consultancy firm responsible for the structural design of the building. Similar to the relationship between the Minnesota Department of Transportation and its main contractor for repair works, the public versus private role patterns were virtually inverted. In reality, it was not the Christchurch City Council who defined what was required for a proper building permit application but the consultancy firm whose drawings and calculations should have been subject to objective scrutiny. How deeply enrooted this pattern was became apparent when, in 1991, the very same consultancy firm was involved in retrofit works concerning the CTV building. The owner did not even think of seeking the indispensable permit of the CCC. This he justified before the Royal Commission with the telling statement that based on his 
personal experience in dealing with the CCC's chief buildings engineer over many years he was convinced that the CCC official would not have asked for such an application anyway. What could appear as arrogance as far as the consultant in his role as a client of the CCC was concerned essentially reflected the erosion of the CCC's institutional integrity.

Accordingly, no intervention took place at the interface between 'situational mechanisms' and 'action formation mechanisms'. Instead, what should have been neutralized as the impact of blurred responsibilities and a weak standing of the CCC was transformed, at the level of 'action formation mechanisms', into the erosion of professional integrity within the CCC's building authority. Moreover, no intervention took place at the threshold between 'action formation mechanisms' and 'transformational mechanisms" either. Potential "near miss" scenarios did occur throughout the 25 years of the CTV building's lifespan. Thorough and diligent "rapid assessments" at the two essential levels (Level 1, Level 2) could have been performed after the initial earthquake of 4 September 2010. Instead, the CCC did neither ensure nor control if the second "rapid assessment" was performed by an engineer which was required by the authority's own rules. As a consequence, the CTV building was declared "structurally sound" after two subsequent inspections which, one more time, was entirely unfounded. What the case of the collapse of the CTV building in Christchurch demonstrates is therefore a key factor that makes that deviance persistent which is lack of leadership in terms of resolve and a strong sense of institutional integrity.

Lack of resolve was certainly not what characterized the attitude of Bad Reichenhall's Lord Mayer. On the contrary, he used his authority to obstruct the renovation of the ice skating rink as decided by the municipal parliament. Similar to the characteristics of the I-35W bridge case but substantially more accentuated was the intra-administrative conflict of interest. The ice skating rink was not a private facility but part of public infrastructure so that the municipality was owner and supervisor of the facility at the same time. This alone made issues of civil engineering and safety vulnerable to politicization. Part of that politicization was, just like in the I-35W bridge case, the constant need of prioritization, especially as far as public spending and investment was concerned. What made the situation peculiar and especially critical as far as safety issues were concerned was that the entire hall complex and its expensive maintenance stood in the way of the urban planning ambitions of the Lord Mayor. The mayor was determined to have the hall dismantled anyway and, consequently, he 
had no intention to 'waste taxpayers' money' for the expensive retrofit in accordance with the decision of the municipal parliament of June 2005.

An intervention at the interface between 'situational mechanisms' and 'action formation mechanisms' could have neutralized the detrimental impact of urban planning ambitions on handling the safety issues connected to the ice skating rink. The Lord Mayor, however, did the opposite when he used his dominant position to purposefully obstruct the decision of the municipal parliament. What should have been subject solely to professional scrutiny in accordance with the expert opinion consulted by the municipality itself - to inspect thoroughly and in detail the roof of the hall where water ingress was notorious-became a bone of contention in local politics.

What makes the collapse of the Bad Reichenhall ice rink specifically tragic is the extremely thin line that separated the disaster of 2 January 2006 from a "near miss" scenario. It was just a matter of minutes. Even though it was in no way connected to the actual fragility of the roof structure-which remained unknown until the post-disaster investigation-the hall manager, after heavy snowfall on that winter's day at the outskirts of the Alps, had the right impulse to evacuate the ice skating rink. So the quasi-instinctive impulse of a last moment intervention was there and, accordingly, the threshold between the 'action formation mechanism' of intended ignorance and the transformational mechanism paving the way to the actual disaster - the last slice of the Swiss cheese, metaphorically speaking - was real. However, the power of 'normalization of deviance' was strong enough to penetrate that threshold: Asked for advice by the hall manager at 3:15PM, an official of the building authority who, according to the findings of the post-disaster criminal trial, had not the slightest idea about the actual conditions on site, told the hall manager to evacuate the ice skating rink at 4:00 PM. It was at 3:55PM that the roof collapsed, killing 12 children and 3 mothers accompanying them (Table 6.1).

While the distinct mechanisms can be identified with the help of theoretical reasoning about organizational pathologies, they are usually known to seasoned practitioners as well. Just like risk zones of particular structural designs in the realm of construction, risk zones of particular organizational arrangements are known to the practitioners of public administration. Situational mechanisms such as organizational fragmentation at the risk of blurred responsibilities and jurisdiction are ubiquitous and inevitable in the relationship between licensing and supervising public authorities and contractors and their subcontractors. It does not come as a surprise 
Table 6.1 Causal Mechanisms, Cross-Case Synopsis

\begin{tabular}{|c|c|c|c|c|}
\hline & $\begin{array}{l}\text { West Gate } \\
\text { Bridge } \\
\text { Melbourne } \\
1970\end{array}$ & $\begin{array}{l}I-35 W \text { Mississippi } \\
\text { River Bridge } 2007\end{array}$ & $\begin{array}{l}\text { CTV-Building } \\
\text { Christchurch } \\
2011\end{array}$ & $\begin{array}{l}\text { Bad Reichenhall } \\
\text { Ice Skating } \\
\text { Rink } 2006\end{array}$ \\
\hline $\begin{array}{l}\text { Situational } \\
\text { mechanisms }\end{array}$ & $\begin{array}{l}\text { Softening } \\
\text { public } \\
\text { authority } \\
\text { through } \\
\text { creating a } \\
\text { QUANGO } \\
\text { [quasi } \\
\text { non- } \\
\text { governmental } \\
\text { organization] } \\
\text { Selznick 1949 } \\
\text { Greve/Flinders/ } \\
\text { Van Thiel 1999 } \\
\text { Flinders/Smith } \\
\text { 1999 }\end{array}$ & $\begin{array}{l}\text { Insufficient } \\
\text { maintenance } \\
\text { funds, } \\
\text { Uncompensated } \\
\text { fragmentation of } \\
\text { jurisdiction } \\
\rightarrow \text { Coordination } \\
\text { issues, } \\
\text { information } \\
\text { asymmetries } \\
\text { Thompson } 1967 \text {, } \\
\text { Akerlof } 1970 \\
\text { Unbalanced } \\
\text { bureaucracy: Red } \\
\text { tape routines in } \\
\text { lieu of case-by- } \\
\text { case scrutiny and } \\
\text { in-depth diligence } \\
\text { Crozier } 1964\end{array}$ & $\begin{array}{l}\text { Blurred } \\
\text { accountability } \\
\text { Olsen } 2014 \\
\text { Latent } \\
\text { hybridity } \\
\text { Denis/Ferlie/ } \\
\text { Van Gestel } 2015 \\
\text { Seibel } 2015\end{array}$ & $\begin{array}{l}\text { Conflict of } \\
\text { interest within } \\
\text { building } \\
\text { authority } \\
\text { (supervisor and } \\
\text { owner at the } \\
\text { same time) } \\
\rightarrow \text { politicization } \\
\text { of professional } \\
\text { issues, especially } \\
\text { maintenance } \\
\text { and inspection } \\
\text { Mintzberg } 1983\end{array}$ \\
\hline $\begin{array}{l}\text { Action formation } \\
\text { mechanisms }\end{array}$ & $\begin{array}{l}\text { Silo-thinking } \\
\text { and selective } \\
\text { perceptions } \\
\text { Dearborn/ } \\
\text { Simon } 1958 \\
\text { Soft regulatory } \\
\text { capture } \\
\text { Dal Bó } 2006 \\
\text { Carpenter/Moss } \\
2014 \\
\text { Blame } \\
\text { Avoidance } \\
\text { Hood 2011, } \\
2014\end{array}$ & $\begin{array}{l}\text { Normalization of } \\
\text { deviance; } \\
\text { Intended } \\
\text { ignorance } \\
\text { Vaughan 1999, } \\
\text { 2016; Seibel 1996 } \\
\text { Goal } \\
\text { displacement } \\
\text { Merton 1940 } \\
\text { Weak defense of } \\
\text { institutional } \\
\text { integrity Selznick } \\
\text { 1957:119-133 } \\
\text { Negotiated safety } \\
\text { Schulman } 1993\end{array}$ & $\begin{array}{l}\text { Normalization } \\
\text { of deviance } \\
\text { Vaughan 1999, } \\
2016 \\
\text { Compromising } \\
\text { professional } \\
\text { integrity } \\
\text { Huntington } \\
\text { 1952 } \\
\text { Seibel 2019 } \\
\text { Selznick } \\
\text { 1957:119-133 }\end{array}$ & $\begin{array}{l}\text { Intended } \\
\text { ignorance } \\
\text { Seibel } 1996\end{array}$ \\
\hline
\end{tabular}


Table 6.1 (continued)

\begin{tabular}{|c|c|c|c|c|}
\hline & $\begin{array}{l}\text { West Gate } \\
\text { Bridge } \\
\text { Melbourne } \\
1970\end{array}$ & $\begin{array}{l}I-35 W \text { Mississippi } \\
\text { River Bridge } 2007\end{array}$ & $\begin{array}{l}\text { CTV-Building } \\
\text { Christchurch } \\
2011\end{array}$ & $\begin{array}{l}\text { Bad Reichenhall } \\
\text { Ice Skating } \\
\text { Rink } 2006\end{array}$ \\
\hline $\begin{array}{l}\text { Transformational } \\
\text { mechanisms }\end{array}$ & $\begin{array}{l}\text { Absence of } \\
\text { leadership and } \\
\text { evaporated } \\
\text { responsibility } \\
\text { Friedrich } 1940 \\
\text { Bovens } \\
\text { 1998:22-44 } \\
\text { Bruttel/ } \\
\text { Fischbacher } \\
2013\end{array}$ & $\begin{array}{l}\text { Absence of } \\
\text { leadership in } \\
\text { terms of } \\
\text { insufficient } \\
\text { coordination and } \\
\text { lack of } \\
\text { mindfulness } \\
\text { Friedrich } 1940 \\
\text { 't Hart/Tummers } \\
2019 \\
\text { Hopkins } 2007 \\
\text { Weick/Sutcliffe } \\
2007\end{array}$ & $\begin{array}{l}\text { Absence of } \\
\text { leadership in } \\
\text { terms of } \\
\text { - lacking } \\
\text { resolve } \\
\text { 't Hart/ } \\
\text { Tummers } \\
\text { 2019:50-51 } \\
- \text { lacking } \\
\text { sense of } \\
\text { responsibility } \\
\text { Friedrich } \\
\text { 1940 } \\
\text { Bovens } \\
\text { 1998:22-44 }\end{array}$ & $\begin{array}{l}\text { Normalization } \\
\text { of deviance } \\
\text { Vaughan 1999, } \\
2016\end{array}$ \\
\hline
\end{tabular}

In italics: Theoretical references

either that, when it comes to action formation, those structural weaknesses have a mind shaping effect on decision makers in charge in the form of silo thinking and selective perceptions, lack of coordination at the expense of professionalism and, ultimately, human safety. Again, however, those are well-known phenomena so that related risk increasing effects are usually kept under control. Put another way, the risk zones at the interface between situational mechanisms and action formation mechanisms are natural zones of intervention. It is here where, under usual circumstances, the undesirable effects of organizational pathologies are being neutralized through regulation, mindful governance and responsible leadership. And even when, by some reason, risk neutralizing intervention was omitted it does take place in most instances at the threshold between detrimental action and a potentially disastrous outcome. Which results in near miss scenarios when disasters are averted at the very last moment.

What the disasters analyzed in this book have in common is that the zones of intervention - the one between situational mechanisms and action formation mechanisms and the one between the latter and transformational mechanisms-were not activated. Not because key actors were 
unable to recognize the risks or because they lacked the skill to draw the necessary consequences. Rather, they did not offer resistance when plausible and attractive excuses presented themselves to ignore the risk zones in the first place. What paved the way to disaster was, in the essence, absence of responsible leadership in various forms. Nobody took the initiative to reintegrate the fragmented organizational structure of construction, consultancy and public oversight and the resulting turf wars when the West Gate Bridge in Melbourne was under construction. No one took care of a comprehensive review of the numerous inspections conducted throughout the lifespan of the I-35W Bridge in Minneapolis. No one was willing to acknowledge, let alone to face the consequences of, the erosion of independence and integrity of the Christchurch City Council vis-à-vis consultants or contractors. And nobody intervened when the Lord Mayor of Bad Reichenhall purposefully ignored the decision of the city's municipal parliament to entirely refurbish the ice skating hall whose roof was obviously in poor shape.

\subsection{LACK OF Mindfulness?}

So the key question remains what accounts for those omissions. In response to that question, the 'usual suspects' in the realm of theory yield unsatisfying results. Certainly, the essentials of the case analyses of this book are in line with Normal Accident Theory (NAT) in the sense that structural risk zones of public control and oversight do exist and need to be addressed when it comes to the construction and maintenance of bridges and buildings. Moreover, in accordance with High Reliability Theory (HRT) the cases also demonstrate the importance of mindfulness. The project management of construction as well as the checking and control procedures of building authorities are necessarily characterized by division of labor that typically involves public administration, contractors and consultants. Certainly, there are structural fault lines within a relatively complex organizational setting so that mindful coordination and interface management is essential. But, again, that is what mindful project managers and public officials usually do without major difficulties.

As a matter of fact, lack of mindfulness is just too vague a notion. It leaves us with little more than the truism that being mindful matters. After all, the question is what exactly may make capable and professional actors neglect what they usually would acknowledge as a challenging but manageable duty of control and coordination in a field where human safety is 
inevitably at stake. What the case studies of this volume reveal is that an appropriate understanding of 'what is at stake' cannot be taken for granted. Key actors were not able or not willing to acknowledge the importance of compliance with existing regulation or, conversely, the potential consequences of poorly coordinated action or just negligence and sloppiness at the expense of proper checking procedures or simple documentation. Hence the question: What were the origins of inability and unwillingness? Rather than assume incompetence-which is rare and, in terms of generalization, lacks any predictive power-it is helpful to think in terms of most likely rationalities and related incentive structures. Which, at the same time, may indicate pathways of strategic learning for the sake of prevention.

An essential part of what the cases studies illustrate is that public bureaucracies are not high reliability organizations by definition and yet need to act like ones under particular circumstances. By its very nature, public administration is exposed to ambiguous requirements of accountability and, thus, legitimacy. ${ }^{2}$ Public agencies need to respond to what citizens like them to do, especially when, at the local level, the action or inaction of authorities impacts directly on the conditions of everyday life. Hence the notion of the "listening bureaucrat" 3 or "street level bureaucracy" ": Public agencies need to be responsive. By the same token, however, public agencies and their representatives cannot be held accountable by individuals or social groups in their immediate societal or political environment alone. They are bound by legislation and to be held accountable in accordance with legal and professional standards. Just as the rigidity of rule-boundedness and protocol entails the risk of inadequate reaction to individual and local requirements, unrestrained responsiveness entails the risk of arbitrariness, clientelism and corruption. The tension between responsiveness and responsibility is part and parcel of public bureaucracy and therefore a risk factor in its own right. ${ }^{5}$

${ }^{2}$ B. Guy Peters: Accountability in Public Administration. In Mark Bovens, Robert E. Goodin and Thomas Schillemans (eds.): The Oxford Handbook of Accountability. Oxford: Oxford University Press 2014, 211-225.

${ }^{3}$ Camilla Stivers: The Listening Bureaucrat: Responsiveness in Public Administration. Public Administration Review 54 (1994): 364-369.

${ }^{4}$ Michael Lipsky: Street-level Bureaucracy: Dilemmas of the Individual in Public Services. New York, NY: Russell Sage Foundation 1980.

${ }^{5}$ Wolfgang Seibel: Are Public Bureaucracies Supposed to be High Reliability Organizations? Global Perspectives 1(1) (2020). 


\subsection{The Responsiveness Versus Responsibility Challenge}

The elementary challenge when it comes to proper conduct of public officials concerned with safety issues is to strike the right balance between the requirements of responsiveness and the requirements of responsibility. In the four cases analyzed in this book that tightrope walking failed. The officials of the Lower Yarra Crossing Authority had every reason to be concerned about the delay of the erection of the West Gate Bridge because the main stakeholders of the authority-representatives of the local and regional business community-expected the expeditious completion of the infrastructure project which was ultimately the result of private initiative and, after all, financed through private loans. The officials of the Christchurch City Council made honest efforts to expedite the checking procedures pertaining to applications for building permits and to cultivate a cooperative relationship with their counterparts among contractors and consultants. A similar kind of partnership and cooperation characterized the conduct of the Minnesota Department of Transportation vis-à-vis contractors for maintenance and repair as well as the department's efforts to improve at least the drivability of the I- $35 \mathrm{~W}$ bridge and to invest taxpayers' money in a new concrete overlay rather than in invisible in-depth inspections of the steel truss structure. And, finally, the Lord Mayor of the city of Bad Reichenhall wanted to respond to the legitimate expectations of citizens concerning the modernization of past time infrastructure instead of spending taxpayers' money for the renovation of an Ice Skating Rink earmarked for demolition. What prevailed in all those cases was the logic of responsiveness that undermined the sense of responsibility of the relevant key actors and made them neglect professional and ethical standards at the expense of human safety.

Which refers to two relevant levels of learning for the sake of prevention. One type of learning is related to what Chris Argyris has denoted as "single loop learning". ${ }^{6}$ It is practical in nature and designed to adapt rules and routines in use, often in the wake of crises and disasters. ${ }^{7}$ Eliminating loop holes in existing regulation, strengthening coordination capacities or

${ }^{6}$ Chris Argyris: On Organizational Learning. 2nd ed., Cambridge: Blackwell 1999.

${ }^{7}$ Cf. for similar assessments Arjen Boin, Allan McConnell, Paul 't Hart: Conclusions: The Politics of Crisis Exploitation. In Boin, McConnell, 't Hart (eds.): Governing after Crisis. The Politics of Investigation, Accountability and Learning. Cambridge: Cambridge University Press 2008, 285-316; D. Christopher Kayes: Organizational Resilience. How 
defining minimal standards for the recruitment of skilled staff are typical examples. Striking an appropriate balance between the requirements of responsiveness and the requirements of responsibility, however, cannot be achieved on a routine basis. This refers to "double loop learning" 8 in the sense of reflecting and, if necessary, adapting the overall premises of the organizational rationale and related civil servant attitudes. When it comes to the responsiveness versus responsibility trade-off, it is about making human safety nonnegotiable even when requirements of responsiveness might recommend otherwise. In the essence, it is about acknowledging the situational logic of high reliability in defense of professional and institutional integrity. ${ }^{9}$ Strategic learning requires to realize the responsiveness versus responsibility trade-off in the first place and to acknowledge the consequences for personal conduct. While the former should be easy to understand and easy to generalize since it comes with the very nature of public bureaucracy the latter remains a challenge to individual judgment and resolve on a daily basis.

Learning Sustains Organizations in Crisis Disaster, and Breakdown. Oxford and New York: Oxford University Press 2015.

${ }^{8}$ Argyris: On Organizational Learning, 67-91.

${ }^{9}$ Philip Selznick: Leadership in Administration. A Sociological Interpretation. Berkeley and Los Angeles: University of California Press 1957, 119-133.

Open Access This chapter is licensed under the terms of the Creative Commons Attribution 4.0 International License (http://creativecommons.org/licenses/ by $/ 4.0 /$ ), which permits use, sharing, adaptation, distribution and reproduction in any medium or format, as long as you give appropriate credit to the original author(s) and the source, provide a link to the Creative Commons licence and indicate if changes were made.

The images or other third party material in this chapter are included in the chapter's Creative Commons licence, unless indicated otherwise in a credit line to the material. If material is not included in the chapter's Creative Commons licence and your intended use is not permitted by statutory regulation or exceeds the permitted use, you will need to obtain permission directly from the copyright holder.

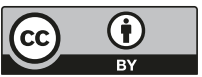

